\title{
One-Electron-Addition to Pentavalent Phosphorus with the Phosphorus-Chlorine Bond as Acceptor Introducing a Fundamental Distinction in Substitution Mechanism between $S_{N} 2(P)$ and $S_{N} 2(C)$
}

\author{
Henk M. Buck \\ Kasteel Twikkelerf 94, Tilburg, The Netherlands \\ Email: h.m.buck@ziggo.nl
}

How to cite this paper: Buck, H.M. (2019) One-Electron-Addition to Pentavalent Phosphorus with the Phosphorus-Chlorine Bond as Acceptor Introducing a Fundamental Distinction in Substitution Mechanism between $\mathrm{S}_{\mathrm{N}} 2(\mathrm{P})$ and $\mathrm{S}_{\mathrm{N}} 2(\mathrm{C})$. Open Journal of Physical Chemistry, 9, 182-191. https://doi.org/10.4236/ojpc.2019.93010

Received: July 29, 2019

Accepted: August 27, 2019

Published: August 30, 2019

Copyright $\odot 2019$ by author(s) and Scientific Research Publishing Inc. This work is licensed under the Creative Commons Attribution International License (CC BY 4.0).

http://creativecommons.org/licenses/by/4.0/

\begin{abstract}
An electron-addition, under single-crystal conditions, to pentavalent phosphorus compounds as $\mathrm{Cl}-\mathrm{P}(=\mathrm{O}, \mathrm{S}) \mathrm{Y}, \mathrm{Z}$ with the $\mathrm{P}-\mathrm{Cl}$ bond as electron-accepting group, is selected as an additional model for $\mathrm{S}_{\mathrm{N}} 2(\mathrm{P})$ like reactions. It is demonstrated that the geometric information stored in the tetrahedral configuration (substrate) can be transmitted in the corresponding trigonal bipyramidal (TBP) state for nucleophilic substitution. In this article, we focus on these specific mechanistic aspects of carbon and phosphorus. We consider our study as a contribution to the significance of these (bio)chemical intermediates.
\end{abstract}

\section{Keywords}

Pentavalent Phosphorus and Carbon Compounds, $\sigma^{\star}$-Electron-Addition, Single-Crystal Electron Spin Resonance (ESR), Model and Ab Initio Calculations, Differences in $\mathrm{S}_{\mathrm{N}} 2(\mathrm{C})$ vs. $\mathrm{S}_{\mathrm{N}} 2(\mathrm{P})$ Mechanism

\section{Introduction}

Our research has correspondence with nucleophilic phosphorus inversion using the smallest nucleophilic agent $\left(\mathrm{e}^{-}\right)$. We focused on pentavalent phosphorus compounds $\mathrm{Cl}-\mathrm{P}(=\mathrm{O}, \mathrm{S}) \mathrm{Y}, \mathrm{Z}$ with an electron-accepting $\mathrm{P}-\mathrm{Cl}$ linkage. The radicals, established with electron spin resonance (ESR) spectroscopy were obtained with single-crystal, powered and host-matrix $\mathrm{x}$-irradiation at low temperature 
[1] [2] [3]. With the dissociation of $\mathrm{Cl}^{-}$, the inverted phosphorus-centered radical can be formed. From the single-crystal studies, it could be established that inter-molecular interactions play a dominant role in the adjustment of the stereochemically controlled electron-addition preference. In fact, these reactions are closely related to Single Electron Transfer (SET) reactions [4].

One-electron-addition accompanied with inversion is shown for a phosphonium cation $\mathrm{R}^{1} \mathrm{R}^{2} \mathrm{R}^{3} \mathrm{P}^{+}-\mathrm{Cl}$ in Figure 1 .

The essential step in Figure 1 is the dissociation of the chloride anion, after electron-addition at the $\sigma^{\star}$-antibonding orbital of the $\mathrm{P}-\mathrm{Cl}$ bond, resulting in the formation of the tetravalent phosphorus-centered radical. The inversion barrier of tetravalent substituted phosphines $\left(\mathrm{R}_{3} \mathrm{P}:\right)$ and their corresponding cationic phosphorus radicals $\left(\mathrm{R}_{3} \mathrm{P}_{\bullet}{ }^{+}\right)$has been described by Creve and Nguyen for simple systems with $a b$ initio MO and DFT calculations [5]. In radical cations, the inversion barriers are consistently and substantially reduced compared with the neutral ones. In fact, we are dealing with a dissociative electron transfer attachment to a molecule with a potentially cleavable bond.

Recently, a study of Nikitin et al. [6] was published on the direct observation of the stereochemical inversion of phosphorus in an $\mathrm{S}_{\mathrm{N}} 2(\mathrm{P})$ reaction via a trigonal bipyramidal (TBP) geometry based on the conventional mechanism. The fluxional interconversions between otherwise very similar bromides and chlorides $\left[\mathrm{R}_{3} \mathrm{P}^{+}-\mathrm{X}\right] \mathrm{X}^{-}(\mathrm{R}=$ Alkyl, Aryl; $\mathrm{X}=\mathrm{Cl}, \mathrm{Br})$ were studied with NMR techniques. The energy barriers are $11 \mathrm{kcal} / \mathrm{mol}$ but rise rapidly as bulky groups are substituted at phosphorus revealing the effect of intra-molecular interactions.

Experimental support for our model description is given in the next section. Three closely related substrates are given under 2.1., 2.2. and 2.3.

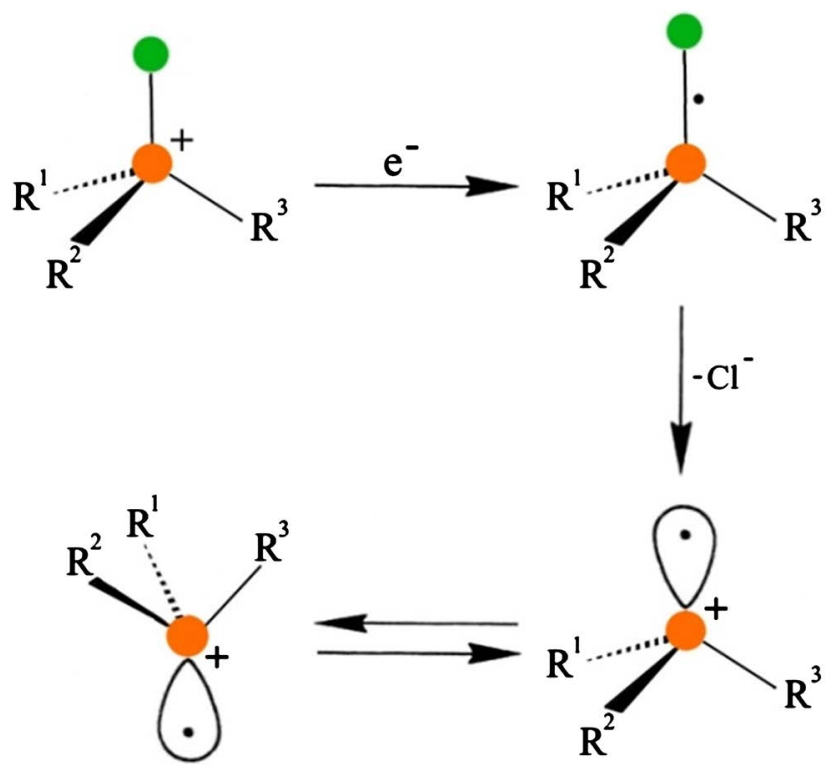

Figure 1. Electron-addition of the phosphonium cation $\mathrm{R}^{1} \mathrm{R}^{2} \mathrm{R}^{3} \mathrm{P}^{+}-\mathrm{Cl}$ and the corresponding inversion of phosphorus. 


\section{Experimental Results and Discussion}

\subsection{Electron-Addition at $2 R, 4 S, 5 R$ and $2 S, 4 S, 5 R$ Stereoisomers of 2-Chloro-3,4di-Methyl-5-Phenyl-1,3,2-0xaza Phospholidine-2-Sulphide}

The x-ray irradiation of the $2 R, 4 S, 5 R(1)$ and $2 S, 4 S, 5 R(2)$ substrates was carried out under single-crystal conditions and low temperature at $77 \mathrm{~K}$ resulting in a high yield and corresponding strong ESR absorptions at $105 \mathrm{~K}$ of $1 \mathrm{a}$ and a very weak ESR signal of $\mathbf{2 a}$ suggesting the impact of geometric inter-molecular interactions. The preparation and molecular structure determination of $\mathbf{1}$ and 2 , their corresponding radical anions and phosphorus-centered radicals are described in Ref. [1].

The inter-molecular interactions could be eliminated by using a host matrix as frozen 2-methyl-tetrahydrofuran (MeTHF). In Figure 2 the electron-addition products $1 \mathrm{a}$ and 2 a are given with their corresponding phosphorus radicals $1 \mathrm{~b}$ and $2 \mathrm{~b}$ respectively.

From representation of the precursors 1 and 2 in the crystal lattice it could be concluded that the shortest interaction of 1 reaches higher values than its isomer 2. This means that increase of the $\mathrm{P}-\mathrm{Cl}$ bond after electron-addition will be better accommodated in 1. In a host matrix as MeTHF this selection is absent. Radical 1a can be detected in the crystal for temperatures up to $225 \mathrm{~K}$, demonstrating its thermal stability. In the MeTHF matrix at $115 \mathrm{~K}$ a fast conversion of $1 \mathrm{a}$ into $\mathbf{1 b}$ takes place demonstrating the effect of the molecular environment. This means that specific atomic movements in the crystal, even the $\mathrm{Cl}^{-}$dissociation, are hindered by the rigidity imposed by the molecular setting. This is certainly the case for the inversion of the phosphorus-centered radicals $(\mathbf{1 b}, \mathbf{2 b})$.

\subsection{Electron-Addition at Di(Pyrrolidino) Chloro Phosphine Sulphide}

The specificity for electron-addition of the $\mathrm{P}-\mathrm{Cl}$ bond has also been observed for

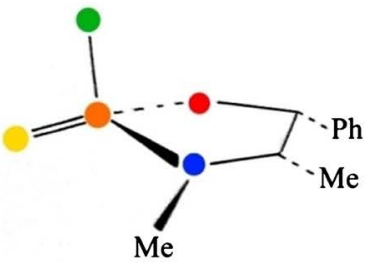

1

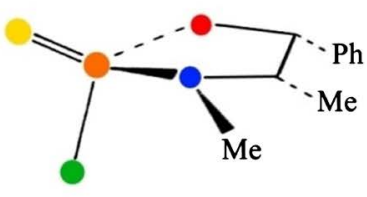

2
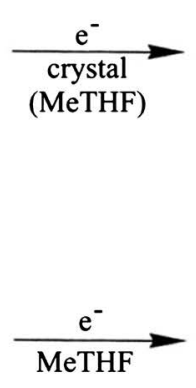

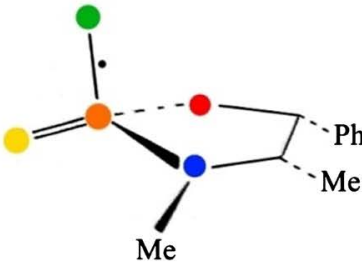

$1 \mathbf{a}$

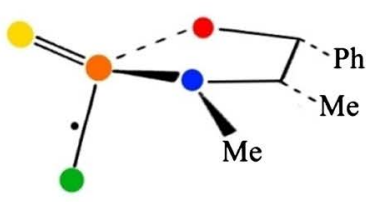

2a

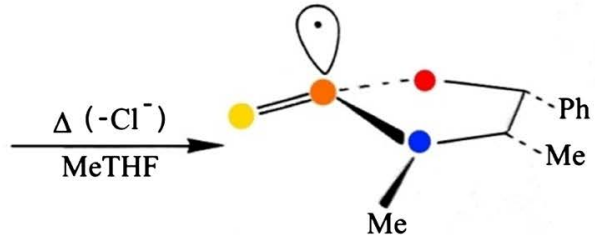

1b

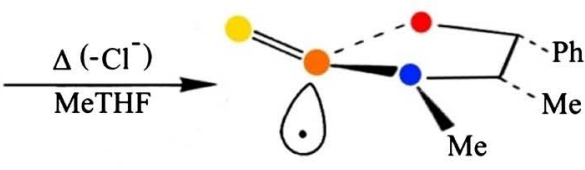

2b

Figure 2. The electron-addition products of 1 and 2 are given with the odd electron localized in the $\sigma^{\star}$-antibonding orbital of the $\mathrm{P}-\mathrm{Cl}$ bond ( $\mathbf{1} \mathbf{a}$ and $\mathbf{2 a}$, respectively) and the phosphorus-centered radicals ( $\mathbf{1} \mathbf{b}$ and $\mathbf{2} \mathbf{b}$, respectively) under thermal dissociation of $\mathrm{Cl}^{-}$. The electron-addition takes place under $\mathrm{x}$-irradiation at low temperature at $77 \mathrm{~K}$ and the ESR spectra at $105 \mathrm{~K}$, and under different conditions as matrix and variable temperatures. 
the related di(pyrrolidino)chlorophosphine sulphide 3 shown in Figure 3 under the same experimental conditions as for the aforementioned compound 1 [2].

For these related electron-addition radicals the ratio of the spin densities on phosphorus and chlorine is between three and four. This preference for localization of the extra electron on phosphorus directs the dissociation towards $\mathrm{Cl}^{-}$.

Generally, the backside attack of the nucleophile or electron is in favor of the frontside attack. However, substitution of chlorine by fluorine results in frontside attack [2]. The selected compound di(morpholino)fluorophosphine sulphide 4 is closely related to the latter one. The preparation and molecular structure determination of 3 and $\mathbf{4}$, their corresponding radical anions and phosphorus-centered radicals are described in Ref. [2]. The results are given in Figure 3 and Figure 4.

\subsection{Electron Addition at Bis (2,4,6-tri-t-ButylPhenyl) Phosphinic Chloride}

Electron-addition followed in-line with the phosphorus-centered radical under inversion of its tetrahedral configuration was observed for the single-crystal electron-addition of bis (2,4,6-tri- $t$-butylphenyl)phosphinic chloride. The preparation and molecular structure determination of $\mathbf{5}$ and the phosphorus-centered radicals are described in Ref. [3]. This result is given in Figure 5.

From the ESR experiments it is clear that $5 \mathrm{~b}$ shows a direct enantioselective stereo-inversion into $\mathbf{5 c}$. In fact, this is the right example to show the unique process procedure in a coupled electron transfer resulting in inversion of the

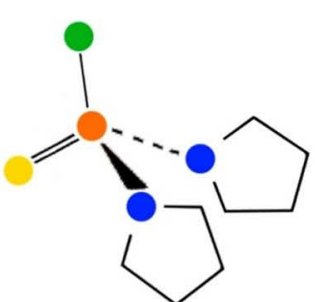

3

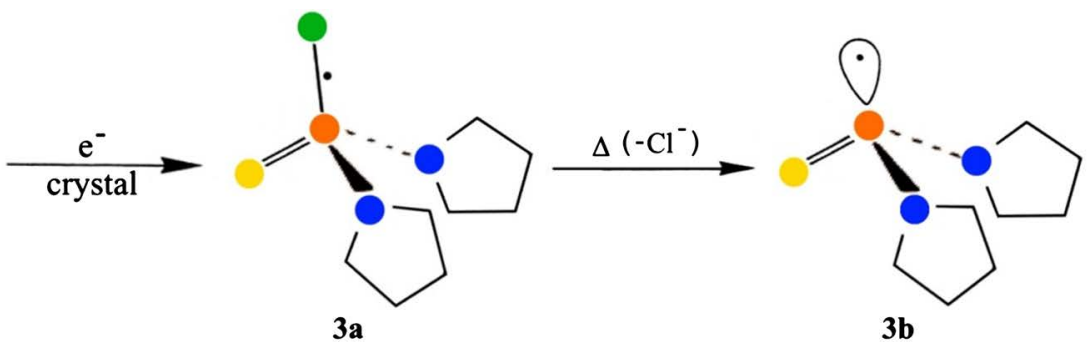

Figure 3. Electron-addition of di(pyrrolidino)chlorophosphine sulphide 3 with the odd electron localized in the $\sigma^{\star}$-antibonding orbital of the $\mathrm{P}-\mathrm{Cl}$ bond (3a) and the phosphorus-centered radical $\mathbf{3 b}$ under thermal dissociation of $\mathrm{Cl}^{-}$.

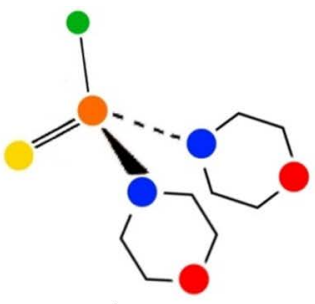

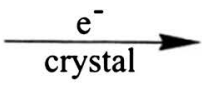

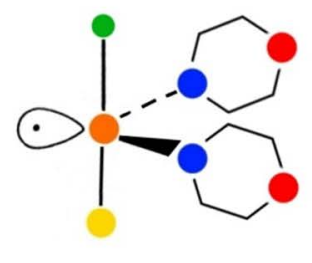

$4 a$

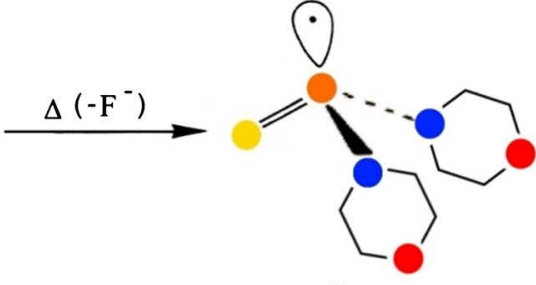

4b

Figure 4. Electron-addition of di(morpholino)fluorophosphine sulphide 4 with the odd electron in an equatorial position of the trigonal bipyramid (TBP-e) and fluorine and sulphur, carrier of the negative charge, in apical positions (4a). Electron displacement in the axis of the TBP results in dissociation of $\mathrm{F}^{-}$and the formation of the radical $4 \mathrm{~b}$. 


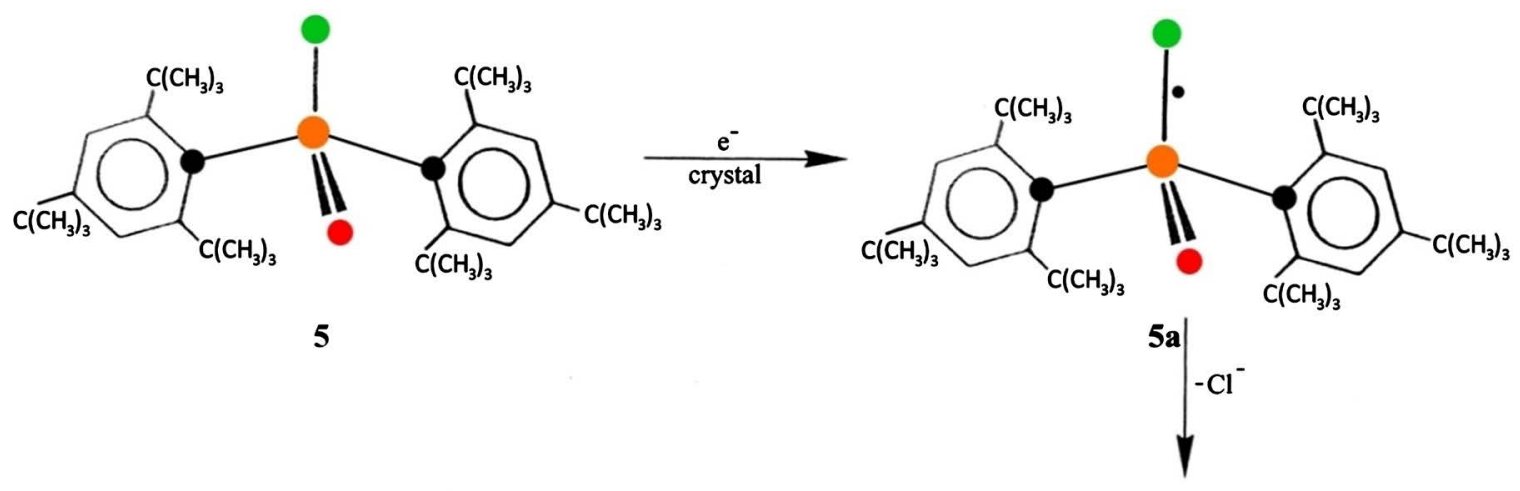
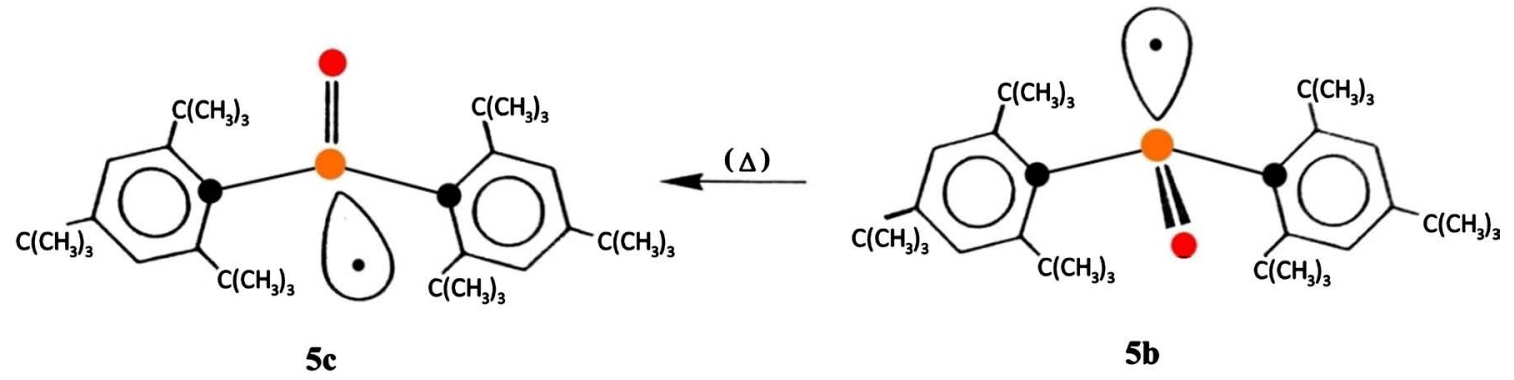

$\mathbf{5 b}$

Figure 5. The electron-addition product of 5 with the odd electron localized in the $\sigma^{\star}$-antibonding orbital of the P-Cl bond $5 \mathrm{a}$ and the phosphorus-centered radical $5 \mathrm{~b}$ under dissociation of $\mathrm{Cl}^{-}$. The electron-addition takes place with $\mathrm{x}$-irradiation at low temperature at $77 \mathrm{~K}$. At $100 \mathrm{~K} 5 \mathrm{~b}$ (dominant) and $5 \mathrm{c}$ (minor) are present. On slow thermal annealing $\mathbf{5 b}$ rapidly disappears with a simultaneous increase of $\mathbf{5 c}$.

tetrahedral phosphorus configuration. This inversion is determined by well-defined intra- and inter-molecular interactions and orientations (influence of the $t$-butyl groups) under single-crystal condition.

It is suggested that the stereo-inversion occurs in a synchronous reorientation of the P-O bond. This conversion is favored by relieve of steric strain in the crystal by relocation of the $\mathrm{P}-\mathrm{O}$ bond to the vacant chlorine space. We consider this unique bond relocation as an example of spatial coordination. This mechanistic mode is an intrinsic property (inversion) of the radical that is triggered by a synchronous $\mathrm{Cl}^{-}$release.

\section{Three-Electron Bonding as a Specific Local Site in the Various Substrates under Investigation}

\subsection{Introduction}

The introduction of specific group-sites in organic systems for accommodation of various modes of bonding focused on different reaction types has been described by us using a variety of (theoretical) models. In that study 3-center 4-, 3-, and 2-electron systems based on carbon-, boron-, hydrogen-, and halogen exchange were considered. Using the number of electrons in the transition state (TS) it is shown that transfer or exchange reactions share the same ratio numbers expressed as the quotient of the transitional bond distance and its normal bond length [7] [8]. With x-ray data of modified systems it was possible to give the ratio numbers for a 3-center 4-electron configuration experimental support 
[7] [8]. In the case of a linear 3-center configuration we used the principal reaction coordinate of a tetrahedral arrangement for the formation of a TBP transition complex. For the number of electrons (2, 3 and 4 ) in these transitions, the corresponding ratio numbers are $1.167,1.250$, and 1.333 . This means that these ratio numbers have no restrictions in their application concerning the migrating particle. As an example for the 3-center 4-electron TS we selected the $\mathrm{S}_{\mathrm{N}} 2$ mechanism simplified by the identity substitution reaction:

$$
\mathrm{X}^{-}+\mathrm{CH}_{3}-\mathrm{X} \rightarrow\left[\mathrm{X}-\mathrm{CH}_{3}-\mathrm{X}\right]^{-} \rightarrow \mathrm{X}-\mathrm{CH}_{3}+\mathrm{X}^{-} \quad(\mathrm{X}=\text { halogen })
$$

In this case, the positively charged methyl migrates between the negatively charged halogens. The TS can then be characterized as a TBP configuration with $\mathrm{X}$ in apical positions. In the most ideal (tetrahedral) configuration, the ratio number for the TS i.e., the ratio between the apical distance and the corresponding bond length in the initial state is $1.333\left(=1-\cos 109.47^{\circ}\right)$ or $1+n / 12$ with $n=4$, the number of electrons. These ratio numbers are indicated as $R(d)$, $R(\theta)$, and $R(n)$, respectively.

A similar result is obtained for the linear proton transfer between carbanions. In that case one is dealing with a divalent hydrogen and in the former case with a pentavalent carbon [7] [8]. The different aspects are supported by ab initio calculations.

The distances $d_{1,2}=d_{2,3}$ for the symmetrically transitional 3-center intermediates can be generally described with:

$$
d_{1,2}=d_{2,3}=R(d, \theta, n) \times d_{1,2(2,3)}
$$

in which $d_{1,2(2,3)}$ are the initial bond distances.

\subsection{Odd Electron Localized in the $\sigma^{*}$-Antibonding Orbital of the Three-Electron P-Cl Bond}

We consider the acceptor with the odd electron in the $\sigma^{\star}$-antibonding orbital of the $\mathrm{P}-\mathrm{Cl}$ bond as a three-center three-electron bonding system. As an example we take the radical anion 1a in Figure 1. With the experimental spin densities of $\mathrm{P}$ and $\mathrm{Cl}$, the ratio number $R(n)$ can then be written as:

$$
R(n)=1+\left[2+\left\{\rho_{\mathrm{s}, \mathrm{p}}(\mathrm{P})+\rho_{\mathrm{s} . \mathrm{P}}(\mathrm{Cl})\right\}\right] 1 / 12
$$

The sum of the spin density $(\rho)$ on $\mathrm{P}$ and $\mathrm{Cl}$ is 0.769 ( $\mathrm{P} 0.577$ and $\mathrm{Cl} 0.192$ ) with $R(n)$ is 1.231 resulting in a $\mathrm{P}-\mathrm{Cl}$ distance of $2.519 \AA$ using $2.047 \AA$ for the initial bond [1]. The increase of the $\mathrm{P}-\mathrm{Cl}$ bond is $0.47 \AA$ and for the dissociation of $\mathrm{Cl}^{-} 0.57 \AA$ is requested which is in accordance with the favored electron-addition at $2 R, 4 S, 5 R$ stereoisomer of 2-chloro-3,4 dimethyl-5-phenyl-1,3,2oxazaphospholidine-2-sulphide with regards to its $2 S, 4 S, 5 R$ stereoisomer as shown in Figure 1.

A related example can be given for the electron capture of an $\mathrm{x}$-irradiated single crystal di(pentavalent-phosphine) disulphide [9] as:

$$
\left[\mathrm{R}_{2} \mathrm{P}(\mathrm{S})-\mathrm{P}(\mathrm{S}) \mathrm{R}_{2}\right]^{-} \text {with } \mathrm{R}=\mathrm{Me}, \mathrm{Et} \text {, and } \mathrm{Ph}
$$


The sum of the spin densities of phosphorus is $0.816(0.840), 0.870$, and 0.830 with corresponding $R(n)$ values of 1.23 (5), 1.23 (7), 1.23 (9), and 1.23 (6). The first two values correspond with two sets of the $\mathrm{R}=$ Me precursors with P-P distances of 2.245 and $2.165 \AA$, respectively. Electron-addition results in distances of 2.773 and $2.678 \AA$. Ab initio calculations for $\mathrm{R}=\mathrm{H}$ give $2.726 \AA$ [9].

A few years ago an $\mathrm{x}$-ray crystal study of an S-S three-electron $\sigma$-bond was published with an S-S distance of $2.817 \AA$ for the cis-parallel phenyl substituents and $2.757 \AA$ for the trans-conformer [10]. Unfortunately, the experimental S-S distance for the dictations is unknown. With the theoretical value of $2.187 \AA$ for $\left[\mathrm{H}_{2} \mathrm{~S}-\mathrm{SH}_{2}\right]^{2+}$ [11] we obtain for $R(d) 1.28(8)$ and 1.26 (1) respectively. For the Se-Se three-electron $\sigma$-bond with cis-parallel phenyl substituents $2.942 \AA$ was established [12]. Using the experimental $\mathrm{Se}^{+}-\mathrm{Se}^{+}$distance of $2.382 \AA$ [13] the $R(d)$-value is $1.23(5)$.

It may be of interest to compare these results with the extensively studied identity 3-center 4-electron $\mathrm{S}_{\mathrm{N}} 2(\mathrm{P})$ conversions [14]. The results are given in the next section.

\subsection{Identity 3-Center 4-Electron $\mathrm{S}_{\mathrm{N}} 2(\mathrm{P})$ Conversions}

The results for this type of conversions are given in Figure 6. The data and geometric structures were obtained from Van Bochove et al. [14].

Clearly, the highest values for $R(d)$ correspond with $7 \mathrm{c}$ and $7 \mathrm{~d}$ indicated as TS. In fact these $R(d)$ values approach 1.25. So, we decided to use the other expression $R(\theta)=1-\cos \theta$. The information stored in the tetrahedral structure can be converted in its corresponding TBP geometry as demonstrated for the $\mathrm{S}_{\mathrm{N}} 2(\mathrm{C})$ for halogen (X) exchange, vide supra, in Table 1 [7] [8].
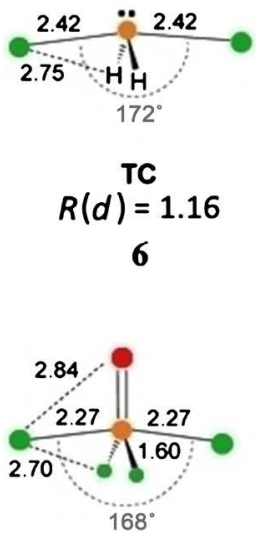

TC $R(d)=1.14$

$7 \mathrm{a}$

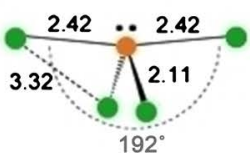

TC $R(d)=1.17$

$6 \mathbf{a}$

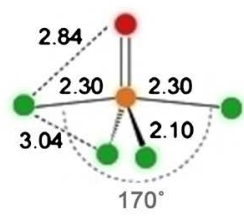

TC

$R(d)=1.14$

$7 \mathbf{b}$

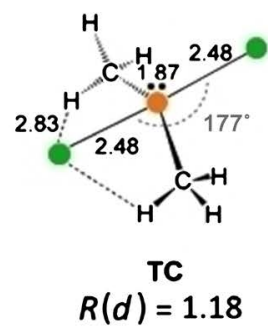

6b

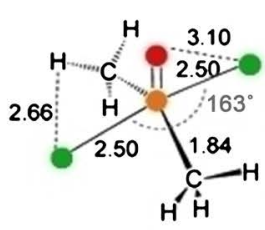

TS

$R(d)=1.21$

$7 c$

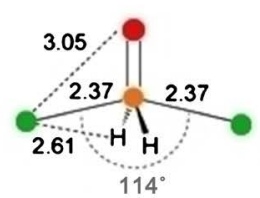

TC $R(d)=1.16$

7

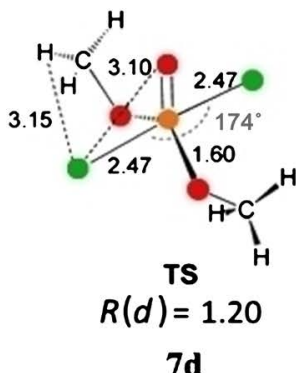

Figure 6. TBP structures of stationary points for $\mathrm{S}_{\mathrm{N}} 2(\mathrm{P})$ in $\AA . .(d)$ values derived from the ratio of the apical distances and corresponding tetrahedral distances (Supporting Information [14]). Stability indication: TC, intermediate transition complex and TS, labile transition state. 
From the results we may conclude that the values of $R(d)$ and $R(\theta)$ are close together. A similar procedure can be followed for the identity chloride exchange $\mathrm{S}_{\mathrm{N}} 2(\mathrm{P})$ in Figure 6. The results are given in Table 2.

For the selected (tetrahedral) choice of $\theta$ (ClPX) we took profit of the mirror-plane symmetry with excluding $\theta(\mathrm{ClP}=\mathrm{O})$ and $\theta(\mathrm{ClP}:)$. In fact there is a good correspondence between $R(d)$ and $R(\theta)$. The deviations are found for $7 \mathrm{a}$ and $7 \mathrm{~b}$. The selection based on the energy profile of the reaction coordinate is opaque because of sufficient lack of information for a definite choice between TC and TS. Interestingly, the difference between the maximum values $R(d)$ and $R(\theta)$ in the case of the $\mathrm{S}_{\mathrm{N}} 2(\mathrm{C})$ and the $\mathrm{S}_{\mathrm{N}} 2(\mathrm{P})$ is 1.33 and 1.25 , respectively. Using the expression $R(n)=1+n / 12$ with $n$ the number of electrons in the three-center bonding for the transition states of both conversions results in four and three electrons, respectively. We suggest that in the latter case the first step may be described as a one-electron transfer accommodated by the $\mathrm{P}-\mathrm{Cl}$ site (see the reaction scheme as given in Figure 1). This means that the latter process undergoes

Table 1. A comparison between $R(d)^{a}$ and $R(\theta)^{b}$ values in combination with the pentavalent carbon state $[\mathrm{XCH} 3 \mathrm{X}]^{-}$.

\begin{tabular}{cccccccc}
\hline Halogen & Method & \multicolumn{3}{c}{ Ab initio $^{a}$} & \multicolumn{3}{c}{ Modeling $^{b, c}$} \\
\cline { 3 - 7 } $\mathrm{X}$ & Level & $d(\mathrm{C}(\mathrm{V})-\mathrm{X})$ & $d(\mathrm{C}(\mathrm{IV})-\mathrm{X})$ & $R(d)$ & $R(\theta)$ & $d(\mathrm{C}(\mathrm{IV})-\mathrm{X})$ & $d(\mathrm{C}(\mathrm{V})-\mathrm{X})$ \\
\hline $\mathrm{F}$ & ZORA-OLYP/TZ2P & 1.860 & 1.396 & 1.332 & 1.322 & 1.383 & 1.828 \\
$\mathrm{Cl}$ & ZORA-OLYP/TZ2P & 2.360 & 1.791 & 1.318 & 1.319 & 1.776 & 2.343 \\
$\mathrm{Br}$ & ZORA-OLYP/TZ2P & 2.510 & 1.959 & 1.281 & 1.304 & 1.934 & 2.522 \\
$\mathrm{I}$ & ZORA-OLYP/TZ2P & 2.720 & 2.157 & 1.261 & 1.319 & 2.132 & 2.812 \\
\hline
\end{tabular}

${ }^{a} R(d)=d(\mathrm{C}(\mathrm{V})-\mathrm{X}) / d(\mathrm{C}(\mathrm{IV})-\mathrm{X})$. The distances $(d)$ are in $\AA .{ }^{b}$ The $R(\theta)$ values from experimental angle ( $\theta$ ) data of the tetrahedral structures using $R(\theta)=1-\cos \theta$. ${ }^{c}$ The corresponding values for the pentavalent state are obtained with $d(\mathrm{C}(\mathrm{V})-\mathrm{X})=R(\theta) \times d(\mathrm{C}(\mathrm{IV})-\mathrm{X})$ using the experimental distances of the tetrahedral structures.

Table 2. Comparison of $R(d)$ and $R(\theta)$ of the stationary points in Figure 6.

\begin{tabular}{ccccc}
\hline no & $R(d)$ & $d\left(\mathrm{P}-\mathrm{Cl}^{\mathrm{ap}}\right)$ & $R(\theta)$ & $d\left(\mathrm{P}-\mathrm{Cl}^{\mathrm{ap}}\right)$ \\
\hline 6 & 1.16 & 2.42 & 1.13 & 2.35 \\
\hline $6 \mathrm{a}$ & 1.17 & 2.42 & 1.20 & 2.48 \\
\hline $6 \mathrm{~b}$ & 1.18 & 2.48 & 1.17 & 2.46 \\
7 & 1.16 & 2.37 & 1.17 & 2.45 \\
$7 \mathrm{a}$ & 1.14 & 2.27 & 1.23 & 2.50 \\
$7 \mathrm{~b}$ & 1.14 & 2.30 & 1.24 & 2.50 \\
$7 \mathrm{c}$ & 1.21 & 2.50 & 1.21 & 2.58 \\
$7 \mathrm{~d}$ & 1.20 & 2.47 & 1.25 & 2.25 \\
\hline
\end{tabular}

The corresponding $R(\theta)$ values are obtained from the theoretical angle data $(\theta)$ of selected tetrahedral configurations (Supporting Information [14]). The P-Clap distance in the last column is obtained using $R(\theta) \times d$ $(\mathrm{P}-\mathrm{Cl})$ with $d(\mathrm{P}-\mathrm{Cl})$, the tetrahedral distance (Supporting Information [14]). 
conversion into the phosphorus-centered radical after dissociation of $\mathrm{Cl}^{-}$with inversion of phosphorus accompanied by $\mathrm{P}-\mathrm{Cl}$ bond formation. Finally, we think that the selected tetrahedral value $\theta(\mathrm{ClPX})$ determines the choice of the reaction coordinate in the $\mathrm{S}_{\mathrm{N}} 2(\mathrm{P})$.

\section{Conclusion}

The basic principle of $\mathrm{S}_{\mathrm{N}} 2$ reactions is that they are bimolecular and occur with inversion of configuration at the reacting atom as demonstrated for carbon. The TS can be described as TBP with incoming nucleophile and leaving group in apical positions. Generally, this model description has been also applied to phosphorus. However, our study shows theoretically fundamental differences between $S_{N} 2(C)$ and $S_{N} 2(P)$ substitution reactions with regard to the participation of the number of electrons in the TS.

\section{Acknowledgements}

I thank Professor Dr. Kirill Nikitin, School of Chemistry University of Dublin, for his valuable discussions.

My grandson Robin van Dorrestein for his technical assistance.

\section{Conflicts of Interest}

The author declares no conflicts of interest regarding the publication of this paper.

\section{References}

[1] Aagaard, O.M., Janssen, R.A.J., DeWaal, B.F.M. and Buck, H.M. (1990) Intermolecular Effects on the Radiogenic Formation of Electron-Capture Phosphorus-Centered Radicals. A Single-Crystal ESR Study of Diastereoisomeric Precursors. Journal of the American Chemical Society, 112, 938-944. https://doi.org/10.1021/ja00159a005

[2] Janssen, R.A.J., Sonnemans, M.H.W. and Buck, H.M. (1986) The $\sigma^{\star}$ and TBP-e Radicals Obtained by Electron Capture of Four-Coordinated Phosphorus Compounds. A Single-Crystal ESR Study. Journal of the American Chemical Society, 108, 6145-6149. https://doi.org/10.1021/ja00280a006

[3] De Waal, B.F.M., Aagaard, O.M. and Janssen, R.A.J. (1991) Enantioselective Inversion of a Chiral Phosphoryl Radical. A Single-Crystal ESR Analysis of X-Irradiated Bis(2,4,6-tri-tert-butylphenyl)phosphinic Chloride. Journal of the American Chemical Society, 113, 9471-9479. https://doi.org/10.1021/ja00025a008

[4] Uchiyama, N., Shirakawa, E. and Hayashi, T. (2013) Single Electron Transfer-Induced Grignard Cross-Coupling Involving Ion Radicals as Exclusive Intermediates. Chemical Communications, 49, 364-366. https://doi.org/10.1039/C2CC37643A

[5] Creve, S. and Nguyen, M.T. (1998) Inversion Processes in Phosphines and Their Related Cations: When Is a Pseudo-Jahn-Teller Effect Operative? Journal of Physical Chemistry A, 102, 6549-6557. https://doi.org/10.1021/jp981083x

[6] Nikitin, K., Jennings, E.V., Sulain, S.A., Ortin, Y. and Gilheany, D.G. (2017) Dy- 
namic Cross-Exchange in Halophosphonium Species: Direct Observation of Stereochemical Inversion in the Course of an $\mathrm{S}_{\mathrm{N}} 2$ Process. Angewandte Chemie International Edition, 57, 1480-1484. https://doi.org/10.1002/anie.201708649

[7] Buck, H.M. (2008) A Combined Experimental, Theoretical, and Van't Hoff Model Study for Identity Methyl, Proton, Hydrogen Atom, and Hydride Exchange Reactions. International Journal of Quantum Chemistry, 108, 1601-1614. https://doi.org/10.1002/qua.21683

[8] Buck, H.M. (2012) Mechanistic Models for the Intramolecular Hydroxycarbene-Formaldehyde Conversion and Their Intermolecular Interactions: Theory and Chemistry of Radicals, Mono- and Dications of Hydroxycarbene and Related Configurations. International Journal of Quantum Chemistry, 112, 3711-3719. https://doi.org/10.1002/qua.24127

[9] Janssen, R.A.J., Sonnemans, M.H.W. and Buck, H.M. (1986) Electron Capture Phosphoranyl Radicals in X-Irradiated Diphosphine Disulfides. A Single Crystal ESR and $A b$ Initio Quantum Chemical Study. Journal of Chemical Physics, 84, 3694-3708. https://doi.org/10.1021/ja00226a013

[10] Zhang, S., Wang, X., Sui, Y. and Wang, X. (2014) Odd-Electron-Bonded Sulfur Radical Cations: X-Ray Structural Evidence of a Sulfur-Sulfur Three-Electron $\sigma$-Bond. Journal of the American Chemical Society, 136, 14666-14669. https://doi.org/10.1021/ja507918c

[11] Gill, P.M.W. and Radom, L. (1989) Structures and Stabilities of the Dimers Dications of First- and Second-Row Hydrides. Journal of the American Chemical Society, 111, 4613-4622. https://doi.org/10.1021/ja00195a014

[12] Zhang, S., Wang, X., Su, Y., Zhang, Z., Qiu, Y. and Wang, X. (2014) Isolation and Reversible Dimerization of a Selenium-Selenium Three-Electron $\sigma$-Bond. Nature Communications, 5, Article No. 4127. https://doi.org/10.1038/ncomms5127

[13] Iwasaki, F., Morimoto, M., Yasui, M., Akaishi, R., Fujihara, H. and Furukawa, N. (1991) Structure of 1,5-Diselenoniabicyclo[3.3.0]octane Bis(tetrafluoroborate) Acetonitrile Solvate. Acta Crystallographica, C47, 1463-1466. https://doi.org/10.1107/S0108270190012586

[14] Van Bochove, M.A., Swart, M. and Bickelhaupt, F.M. (2006) Nucleophilic Substitution at Phosphorus (SN2@P): Disappearance and Reappearance of Reaction Barriers. Journal of the American Chemical Society, 128, 10738-10744.

https://doi.org/10.1021/ja0606529 